\title{
AC 2008-1698: PREPARING GRADUATE STUDENTS TO BE SUCCESSFUL AS TEACHING MENTORS AND AS FUTURE PROFESSIONALS
}

\section{Tershia Pinder-Grover, University of Michigan}

Tershia Pinder-Grover (tpinder@umich.edu) is the Coordinator of Engineering Graduate Student Instructor (GSI) Initiatives at the Center for Research on Learning in Teaching at the University of Michigan. She oversees the Engineering GSI Mentor (EGSM) Program, plans teacher training for new engineering GSIs, develops workshops and seminars, and consults with faculty and GSIs on pedagogy and engineering education research projects. Dr. Tershia Pinder-Grover earned her B.S. degree in Fire Protection Engineering from the University of Maryland and her M.S. and $\mathrm{Ph} . \mathrm{D}$. degrees in Mechanical Engineering from the University of Michigan. While in graduate school, she served as an Engineering GSI Mentor.

\section{Sarah Root, University of Arkansas}

Sarah Root (seroot@uark.edu) is an Assistant Professor of Industrial Engineering at the University of Arkansas. Her research interest is in applied operations research, particularly large-scale scale optimization of transportation, logistics, and healthcare systems. While she was completing her dissertation at the University of Michigan, she participated for three years in the EGSM program.

\section{Emine Cagin, University of Michigan}

Emine Cagin (cagin@umich.edu) received her bachelor's of science degree from Worcester Polytechnic Institute in 2003, and her master of science degree from the University of Michigan in 2007. Both of her degrees are in electrical engineering. She is currently pursuing a $\mathrm{PhD}$ in electrical engineering at the University of Michigan's Solid State Electronics Laboratory. Emine is currently serving as a mentor in the EGSM program. 


\title{
Preparing Graduate Students to be Successful as Teaching Mentors and as Future Professionals
}

\begin{abstract}
Graduate student instructors (GSIs) - or teaching assistants - are a critical resource upon which many large research institutions rely. The GSI position also provides a pivotal opportunity for developing the next generation of engineering faculty and industry leaders through training and mentoring. A centrally organized peer mentor program $^{1}$ is one approach that can positively impact not only the GSIs' teaching experiences, but the peer mentors' experiences as well. ${ }^{2}$ This paper evaluates the Engineering GSI Mentor (EGSM) program at the University of Michigan, which is designed to train and empower selected graduate students to provide teaching-related services to their fellow GSIs. EGSMs' duties range from consultations on a variety of pedagogical topics to in-classroom services, such as observing a GSI's teaching and eliciting feedback from a GSI's students. Furthermore, EGSMs consult on general graduate student issues such as advisor-advisee relationships and time management strategies. EGSMs work in teams to develop and facilitate well-attended workshops of interest to all graduate students. Workshops focus on academic as well as professional themes, and are aimed at helping participants define and accomplish their goals through graduate school.
\end{abstract}

In this paper, we discuss the training that EGSMs receive as teaching consultants and mentors to their fellow graduate students. In particular, we describe the training curriculum that has been developed to help prepare EGSMs for their roles. Topic areas covered in the curriculum and the format in which the training is delivered are discussed. Our data are obtained from a survey of current and former EGSMs. We conclude by describing how both the formal professional development sessions and the on-the-job training and experiences helped to prepare alumni of the EGSM program for their careers in both industrial and academic settings.

\section{Introduction}

Graduate students carry out a significant portion of the teaching activities in many engineering colleges within large research institutions. In order to maintain a high quality of teaching, and to provide opportunities for graduate students to grow as teachers, the University of Michigan College of Engineering pays special attention to the training of GSIs. The Center for Research on Learning and Teaching (CRLT) administers a day-long training program for new GSIs. EGSMs help run this training day, and then continue to mentor both new and experienced GSIs throughout the semester.

EGSMs are a group of experienced GSIs who have expressed interest in further involvement with the study of teaching and learning. They are selected through a competitive application and interview process. EGSMs receive training specific to preparing new GSIs for their first teaching assignments prior to the beginning of the semester. Afterwards, on-the-job training runs primarily through bi-weekly topical meetings of the mentors. We discuss the details of the EGSM training in Section 2.2. 
Different approaches to mentoring GSIs currently exist in current literature and practice. We studied examples of previously implemented faculty-student mentoring, peer mentoring in pairs, and centralized peer mentoring programs for comparison with the EGSM initiative.

Faculty-graduate student teams can effectively give the GSI a teaching internship opportunity where the GSI shares the teaching responsibilities with a faculty mentor ${ }^{3,4,5}$ or even serves as the primary instructor with the faculty member in a supervisory role. ${ }^{6}$ In some cases, faculty- and GSI-development professionals provide consulting and mentoring services. ${ }^{7}$ This technique has proved effective for helping the graduate student grow as a teacher and prepare for an academic career. While these mentoring relationships can be extraordinarily productive, they also can be highly variable in quality because of the individualized nature of the experience.

A different approach is to incorporate senior graduate students as a resource for mentoring less experienced graduate students, especially in relation to teaching practices. Some peer-mentoring programs arrange graduate students into pairs, where the pair can establish a long-term, one-onone mentor-mentee relationship. Bollis-Pecci and Walker point out that this kind of pairing benefits not only the mentee, but also the mentor in the form of opportunities for reflection, as well as original perspectives and ideas coming from the less experienced GSI. ${ }^{8}$

Centralized mentoring programs provide the most direct comparison to the EGSM program in which all authors were participants, and which we discuss in this paper. One example of a centralized program is The Lead Network at the University of Colorado at Boulder. This program provides an intensive and thorough training week before consultants start their work with GSIs. ${ }^{9}$ The training covers learning theories and consultation techniques, as well as practical information on providing services such as videotaping classes and observing classrooms. Another example of centralized mentoring programs is the Teaching Consultants group at Harvard University. ${ }^{10}$ Similar to The Lead Network, Teaching Consultants at Harvard have an intensive training period prior to the start of the consultants' interactions with GSIs. The training typically lasts two to three days, and topical meetings throughout the semester follow. In both of these examples, end-of-term surveys help assess the satisfaction and benefits mentors receive from the program. Both programs have collected anecdotal information pointing to the mentors acknowledging that they grow as teachers and consultants through their training and participation.

In this paper, we focus on the benefits of such programs to the mentors, and discuss how their experiences mentoring their peers have impacted the alumni and current members of the University of Michigan's College of Engineering Graduate Student Mentor program. We investigate the benefits that the mentors receive from being part of the EGSM program as applied to their subsequent careers.

In particular, we address the following questions in our study:

1. How does the formalized and on-the-job training benefit the EGSMs during their tenure as a mentor and beyond?

2. What learning outcomes are enhanced or developed for the mentors through the EGSM program?

3. How does the EGSM program impact the teaching practices, mentoring, and career direction of participants? 


\section{The EGSM Program}

In this section, we describe the structure of the EGSM program, the services that the peer mentors provide, and the training that the peer mentors receive. This context will be helpful in understanding the benefits that EGSMs receive as a result of their participation in the program. (Note that O'Neal and Karlin ${ }^{1}$ have described this program in detail previously). The initial goal in the creation of the EGSM program was to address the challenge of providing training and ongoing support for a large number of GSIs whose roles and responsibilities may change from semester to semester. ${ }^{1}$ Throughout the evolution of the program, its primary objective has remained unchanged: to identify, train, and empower selected graduate students, who have previously served as GSIs, to provide teaching support through peer consultation.

Each semester, a staff member at the University's teaching center selects approximately ten graduate students to serve as EGSMs through a competitive interview process. The program is a partnership between the office of the Associate Dean for Research and Graduate Education in the College of Engineering, who provides the financial support, and the university's teaching center (CRLT), which coordinates the program and supervises the mentors' training. Full details of the selection process are included in the article by O'Neal and Karlin, ${ }^{1}$ but essentially mentors must serve at least one semester as a GSI at the University of Michigan as a pre-requisite for applying to the program. EGSMs demonstrate a passion for teaching and helping their peers develop their teaching. Many of them have significantly more than one semester of teaching experience, making them better able to draw from practical first-hand experiences when providing guidance to their peers. For instance, the 10 EGSMs who served in the Fall 2007 semester had an average of 3.5 semesters of teaching experience. In comparison, $81 \%$ of the CoE GSIs who responded to the Fall 2007 GSI survey $(\mathrm{N}=100 / 123)$ indicated that they have only taught for $1-2$ semesters. $^{10}$

\subsection{EGSM Services}

A program coordinator from the teaching center assigns every engineering GSI, approximately 225 each semester, to an EGSM in the beginning of each term. Each peer mentor works directly with 20-25 GSIs, although their services are available to all GSIs. Some EGSM services are interactions with individual GSIs, while others are interactions with multiple GSIs simultaneously. During the 2006-2007 academic year, there were 483 individual consultations (scheduled, by email, or casual face-to-face interactions) and 86 classroom interventions. ${ }^{12}$ Additionally, 155 GSIs attended group consultations and 105 GSIs participated in seminars run by EGSMs. ${ }^{12}$ These services include:

- Individual consultations: One-on-one discussions on issues such as effective teaching strategies, time management, and GSI-faculty interactions.

- Classroom interventions: Midterm student feedback sessions (also known as small group instructional diagnostics (SGID) or small group analysis (SGA)), classroom observations, and videotaped class sessions with follow up consultations.

- Group consultations: Small group discussions on topics such as developing transition materials for laboratory courses and providing career advice for graduating seniors.

- Seminars on teaching: Workshops on topics such as grading issues, handling office hours, and managing student teams during new Engineering GSI training and during the semester. 
Two previous papers discuss the details of these interactions. ${ }^{1,2}$ It is important to note that EGSMs typically interact with their assigned GSIs several times throughout the term, and they gradually establish a long-term mentoring relationship.

Immediately preceding the beginning of the semester, EGSMs help run a one-day training session for new GSIs to equip them with skills to to succeed as teachers. Attendance is mandatory for all new GSIs. During the day EGSMs facilitate workshops on a wide range of topics. This day is an excellent opportunity for EGSMs to introduce themselves to new GSIs personally. Once classes begin, EGSMs periodically contact all GSIs assigned to them -new and returning - to find out if they have any questions or concerns about their classes, and to notify them of upcoming seminars. In addition, EGSMs are available for one-on-one interactions, which can lead to teaching-related conversations, brainstorming potential resolutions to issues faced by GSIs, or midterm student feedback (MSF) sessions that are facilitated by the EGSM. All interactions between EGSM and GSIs are confidential; the mentors do not report the content of their discussions with GSIs to departmental or college authorities. Typically EGSMs are rated very highly by their peers as discussed in previous research on this program. ${ }^{1,2}$

\subsection{EGSM Training}

The Center for Research on Learning and Teaching and an associated program manager train the EGSMs to enable the new and returning mentors to successfully fulfill their roles as peer mentors. EGSMs receive multifaceted training prior to interacting with GSIs, and throughout their tenure in the program. The EGSM training makes up a comprehensive curriculum with the following constituent pieces:

- Training on practice teaching facilitation: mentors learn how to direct new GSIs to reflect on their teaching during a 5-7 minute mock-lesson, provide feedback, and facilitate small group feedback from 5-6 new GSIs who also participate in the lesson. ${ }^{13}$

- Training on conducting classroom observations and Midterm Student Feedback (MSF) sessions: mentors learn how to observe classes, collect student feedback, and consult with GSIs on the collected data.

- Biweekly topical meetings: mentors gather to receive on-going professional development (discussed in detail below).

- Mentoring within the EGSM program: experienced EGSMs currently in the program mentor new EGSMs through shadowing experiences, answering questions, and reviewing reporting materials and email correspondence.

The training sessions on practice teaching facilitation and on conducting classroom observations and MSFs occur once, typically in the first few weeks of an EGSM's tenure. These interactive sessions coach EGSMs in facilitating fruitful discussions and working with GSIs to reflect on their teaching. The biweekly meetings and mentoring within the program occur on an ongoing basis. Each semester, all EGSMs are required to attend the biweekly professional development meetings.

Biweekly meetings are typically divided into two parts. First, EGSMs examine issues they have observed with their GSIs during a roundtable discussion. The issues are varied, but typically involve situations where a GSI asks an EGSM for advice. Together, the EGSMs brainstorm how 
these sometimes unwieldy situations can be handled. Currently, an EGSM facilitates the roundtable discussion, and limits the duration to approximately 20 minutes.

Second, we engage in a more formal training session that is typically conducted by a program manager. Since Fall 2005, these training sessions have become more formalized with the creation of a training curriculum. This curriculum stresses six major content areas: procedures and responsibilities, consulting, data collection, pedagogy, scholarship of teaching and learning, and special topics. We select the special topics based on the interests of EGSMs (Table 1). At least one topic is selected from each category each semester, and in some cases topics are combined to address the needs and interests of the specific group of EGSMs present. The overall goal is to highlight information in all of these areas by the end of the term.

The Associate Dean for Research and Graduate Education for the College of Engineering (and sometimes college administrators) visit at least one of these sessions per semester to discuss GSI needs and perceptions. In this manner, EGSMs have a voice in expressing the needs of GSIs to the administration.

Table 1. Training Topics for Engineering Teaching Mentors

\begin{tabular}{|c|c|}
\hline Purpose & Potential Topics \\
\hline Procedures and Responsibilities & $\begin{array}{ll}- & \text { Expectations } \\
- & \text { Resources } \\
\text { - } & \text { Reporting Requirements }\end{array}$ \\
\hline Consulting & $\begin{array}{ll} & \text { GSI/TA Development } \\
\text { - } & \text { Consultation Case Studies } \\
\text { - } & \text { Consulting in Different Classroom Environments } \\
\end{array}$ \\
\hline Data Collection & $\begin{array}{ll}\text { - } & \text { Office Hour Observation } \\
\text { - } & \text { Videotaped Consultation } \\
\text { - } & \text { Midterm Student Feedback Report Reviews }\end{array}$ \\
\hline Pedagogy & $\begin{array}{ll}\text { - } & \text { Learning Styles } \\
\text { - } & \text { Inclusive Classrooms } \\
\text { - } & \text { Group work } \\
\end{array}$ \\
\hline $\begin{array}{l}\text { Scholarship on Learning and } \\
\text { Teaching }\end{array}$ & $\begin{array}{ll}\text { - } & \text { Evaluating Methods to Improve Teaching }{ }^{18} \\
\text { - } & \text { Academic Integrity }{ }^{19} \\
\text { - } & \text { Student Evaluations }\end{array}$ \\
\hline Special Topics & $\begin{array}{ll}\text { - } & \text { Authority Issues } \\
\text { - } & \text { GSI-faculty team relationships } \\
\text { - } & \text { Instructional Technology }\end{array}$ \\
\hline
\end{tabular}

A final element of the training that EGSMs receive is informal mentoring from their peer EGSMs. All new EGSMs are assigned at least one mentor from the pool of more experienced EGSMs. This provides new mentors with a natural mechanism through which they can ask questions, get feedback, and develop their individual consulting skills. This mentor also accompanies the new EGSM when he or she completes an MSF (or some other responsibility) for the first time. They also share resources that they have developed such as sample reports of classroom observations, characteristic e-mails that they have sent to their GSIs and so on.

\section{Methodology}

To explore the impact of the EGSM experience on the mentor, we developed an online survey. We used the detailed knowledge of the EGSM training we have while designing the survey, and 
obtained approval from our university's Institutional Review Board to conduct the survey on former and current EGSMs. Recall that our focus for this study is on those doing the mentoring rather than those receiving the mentoring, and our research questions are as follows:

1. How does the formalized and on-the-job training benefit the EGSMs during their tenure as a mentor and beyond?

2. What learning outcomes are enhanced or developed for the mentors through the EGSM program?

3. How does the EGSM program impact the teaching practices, mentoring, and career direction of participants?

The survey was adapted from Meizlish and Wright ${ }^{20}$ and included (a) questions about career choices, with respondents in academia providing information about their institutional context and postsecondary teaching experiences and graduate students sharing their potential career choices; (b) items associated with the value of the GSM training and what they learned from the program; (c) questions about their teaching practice, mentoring, and influences on their career decision; and (d) open-ended questions for respondents to provide examples associated with their teaching practice, mentoring, and influences on career decisions. We include the survey questions in the Appendix.

All 52 participants of the Engineering GSM program from Winter 2001-Fall 2007 were directed to an online survey developed in SurveyMonkey via e-mail. The response rate for the survey was $58 \%$ (30 out of 52). In our analysis, the quantitative analysis was primary. We report descriptive statistics and provide illustrative quotes to further illuminate key numerical findings.

\section{Respondents}

We highlight the career selection of the respondents (Figure 1) and describe the institutional context for all of the respondents who work in an academic setting. Approximately $40 \%$ of respondents are currently graduate students $(\mathrm{N}=12), 34 \%$ have careers as lecturers or tenured/tenure track faculty $(\mathrm{N}=10)$, approximately $20 \%$ are research scientists or engineers in industry $(\mathrm{N}=6), 3 \%$ of respondents work in faculty development $(\mathrm{N}=1)$ and $3 \%$ of respondents self-identified as a technical consultant $(\mathrm{N}=1)$. Sixty-seven percent of the graduate students were currently serving as mentors at the time of the survey. No respondents had a career as a higher education administration (other than faculty/graduate student development) or as a research scientist in academia or a national research laboratory.

Twenty-three of the 30 respondents are associated with academia as faculty, staff, or student. The majority of these respondents, $83 \%(\mathrm{~N}=19)$, work in a research university, while $13 \%(\mathrm{~N}=3)$ are at a comprehensive/master's university. One respondent indicated that they taught at a "specialized engineering and science university." No respondents were associated with liberal arts or community/two-year colleges. For the purposes of discussion, we categorize the responses in this study as (a) overall respondents, (b) graduate students, (c) academic track respondents (including tenured and tenured-track faculty and lecturers), and (d) research scientists or engineers in industry. 


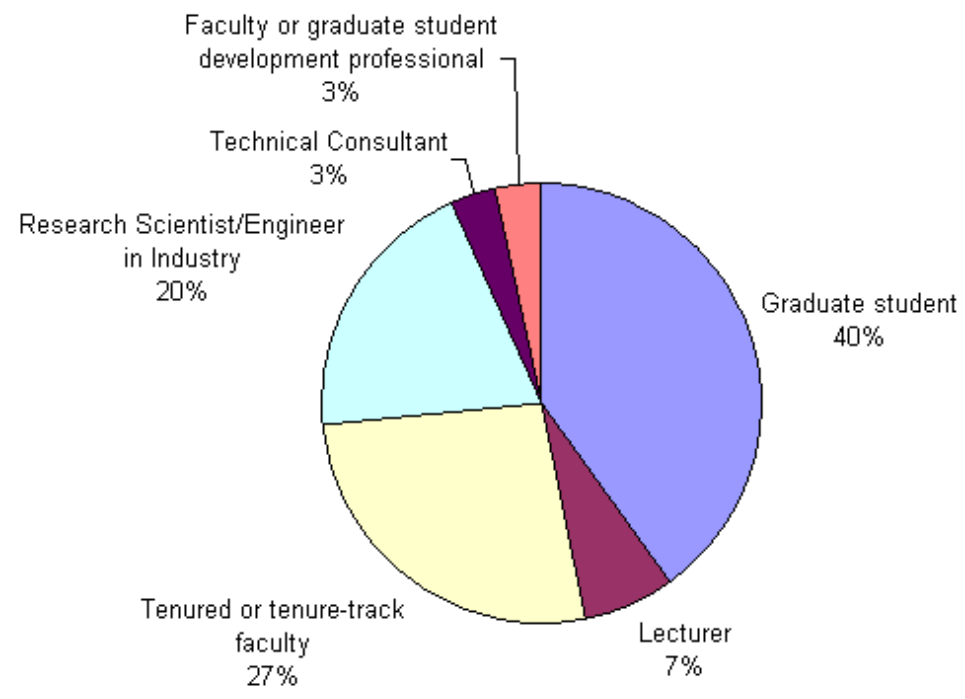

Figure 1. Respondent Career Selection

\section{Presentation and Discussion of Findings}

We used the responses to the survey combined with the information on the respondents themselves to address the research questions under investigation. In particular, in this section we describe the benefits of the training, the mentors' specific learning outcomes, and the explicit impact of the program on respondents who are in graduate school, academia, and industry.

5.1. How does the formalized and on-the-job training benefit the EGSMs during their tenure as a mentor and beyond?

Previously we described four aspects of the EGSM training: (1) training on practice teaching facilitation, (2) training on conducting classroom observations and midterm student feedback, (3) biweekly meetings with roundtable discussions, and (4) mentoring within the EGSM program. Although the program has evolved over the years, all mentors in this study participated in the first three elements, where the content of the biweekly meetings has changed in time. Mentoring within the EGSM program was informally implemented earlier; however, the degree to which mentors interacted with one another varied from participant to participant. To support these informal mentoring relationships, we have assigned mentors and provide suggested guidelines for mentoring within in the EGSM program to all participants since Winter 2007.

In our survey we asked EGSMs, "What aspects of the training that you received as [an EGSM] were most valuable to you when you were a [mentor]?" Seventeen out of 30 participants responded to the question. This lower response rate could be because some respondents may not remember all of the training details. We also separated out the roundtable discussion from the 
ongoing professional development to better understand the specific impact of each aspect of the biweekly meetings.

Table 2. EGSM Training Elements Identified as Most Valuable

\begin{tabular}{|c|c|c|}
\hline Formalized and On-the-Job Training & \multicolumn{2}{|c|}{ Overall* } \\
\hline & $\mathbf{\%}$ & $\mathbf{N = 1 7}$ \\
\hline GSM roundtable discussions & 82 & 14 \\
\hline MSF and classroom observation training & 77 & 13 \\
\hline GSM biweekly meetings & 71 & 12 \\
\hline Mentoring of new GSMs by experienced GSMs & 65 & 11 \\
\hline Practice teaching facilitation training & 36 & 6 \\
\hline \multirow{2}{*}{ (Respondents could choose more than one category). } \\
\hline
\end{tabular}

EGSMs overwhelmingly identify the roundtable discussions as one of the most valuable aspects of their training. In particular, one EGSM stated, "[The roundtable discussions] increased my general awareness ... about various classroom issues e.g. gender, cultural/academic backgrounds of the students and how an instructor should handle such issues." While another mentor identified the ability to have "several new concrete techniques for handling specific types of situations," as an important benefit of the roundtable discussions.

Over $70 \%$ of all respondents believed that the training on conducting classroom observations and midterm student feedback sessions, as well as the professional development component of the biweekly meetings, were most valuable. One graduate student said, "The training provided to [EGSMs] makes me more aware of how I am teaching and how I can improve." Over $60 \%$ of the respondents found the mentoring within the EGSM program the most valuable. It is interesting to note that all of the respondents who are currently working in industry as a research scientist or engineer found the internal mentoring as one of the most valuable aspects to the training. We believe the mentoring that a newly hired engineer or scientist could receive, and subsequently the mentoring that these engineers or scientists could provide to others as they progress through their careers in an industrial setting, can help explain this result.

Participation in the practice teaching facilitation training may be perceived as less valuable to the mentors (36\%), because they are more likely to observe a GSI's classroom teaching than conduct a practice teaching session during the term. All new Engineering GSIs participate in two practice teaching sessions - one focusing on delivering a lesson or role playing an office hour and a second session engaging students in a lesson using active learning ${ }^{13}$ — therefore, GSIs at our institution are less likely to request additional practice teaching sessions. If a GSI whose primary responsibility is to hold office hours requests feedback, then it is likely that an EGSM would conduct a practice session beyond the beginning of the term.

Additional experiences that participants found helpful included conversations with faculty developers from the teaching center and participation in preparing future faculty seminars. It is also important to note that the EGSM training goes beyond the four areas we describe. One respondent said, "I value the experience ... of being a facilitator of different sessions such as the 
roundtable sessions, [the teaching center's] workshops and GSI training workshops." These facilitation moments provide reinforcement of the concepts taught in the biweekly meetings, roundtable topics and facilitation training. A respondent from industry summarized his perception of the EGSM training experience experiences as, "[I] have applied lessons learned from each of these aspects to my current job ... I can lead a team better, and I know how to develop and teach a course."

5.2 What learning outcomes are enhanced or developed for the mentors through the EGSM program?

In a previous study about the EGSM program, ${ }^{2}$ the overall benefits to the mentor included: (1) remaining involved in teaching while "progressing with their technical research," (2) learning about the scholarship of learning and teaching, (3) discussing teaching-related issues with their peers to increase their "breadth of teaching experiences," (4) being exposed to different classroom situations through interactions with other GSIs, (5) receiving personal satisfaction through providing a service to peers in the College of Engineering, and (6) developing their academic credentials by becoming more attractive candidate through their participation.

To determine specific learning outcomes associated with participating in the Engineering GSM program, we asked the respondents in this study, "Which of the following experiences were either developed or enhanced as a result of your participation in the EGSM program?" Responses are loosely categorized in terms of factors associated with teaching, mentoring, and professional skills. Twenty-seven of the 30 respondents answered with 26 respondents identifying the top responses as "learning more about teaching and student learning (pedagogy)" and "learning how to improve your own teaching in the classroom." Comparably, faculty mentors identified similar benefits when they participated in teaching internships because they were able to think about ways to effectively present material and assess student learning. ${ }^{6}$ Twenty-four respondents felt they learned how to handle different classroom challenges. These teaching-related benefits confirm the assertions described by Hancock et. al. ${ }^{2}$

While benefits related to growth as a teacher were the most frequent responses to this survey question, 25 respondents also agreed that learning how to provide feedback to others was another important skill they developed through being a peer mentor. One graduate student stated, "In the EGSM program I [learned] a lot about giving effective feedback and consulting with GSIs. I have started using these techniques when I interact with my students and the undergrads who help me in my research work. I have noticed a change in the focus of my feedback - from feeling the need to make my point to thinking how the feedback would help the students."

Table 3 shows how respondents value different learning experiences based on their career choice. As expected, respondents who work in academia (faculty or lecturers) value teachingrelated benefits to participating in the EGSM program. Engineers or research scientists in industry value the opportunity to improve their own teaching, but also providing feedback to others. Over $80 \%$ of engineers in industry identified time management skills as another indirect benefit of participating in the EGSM program. 
Individual respondents identified learning about group collaborations and dynamics as specific learning experiences from the program. Finally, one lecturer developed more classroom confidence by "providing feedback to others ... because I felt it was normal to always be revising and improving what I do in the classroom."

Table 3. Enhanced or Developed Learning Experiences that Occurred through the EGSM program

\begin{tabular}{|c|c|c|c|c|c|c|c|c|}
\hline \multirow[t]{2}{*}{ Learning Experiences } & \multicolumn{2}{|c|}{ Overall* } & \multicolumn{2}{|c|}{$\begin{array}{l}\text { Faculty or } \\
\text { Lecturer }\end{array}$} & \multicolumn{2}{|c|}{$\begin{array}{c}\text { Engineer or } \\
\text { Research } \\
\text { Scientist }\end{array}$} & \multicolumn{2}{|c|}{$\begin{array}{l}\text { Graduate } \\
\text { Student }\end{array}$} \\
\hline & $\%$ & $N=27$ & $\%$ & $N=9$ & $\%$ & $N=6$ & $\%$ & $N=11$ \\
\hline $\begin{array}{l}\text { Learning more about teaching and student } \\
\text { learning (pedagogy) }\end{array}$ & 96 & 26 & 100 & 9 & 83 & 5 & 100 & 11 \\
\hline $\begin{array}{l}\text { Learning how to improve your own } \\
\text { teaching in the classroom }\end{array}$ & 96 & 26 & 100 & 9 & 100 & 6 & 91 & 10 \\
\hline $\begin{array}{l}\text { Learning how to provide feedback to } \\
\text { others }\end{array}$ & 93 & 25 & 89 & 8 & 100 & 6 & 91 & 10 \\
\hline $\begin{array}{l}\text { Learning how to handle different } \\
\text { classroom challenges }\end{array}$ & 89 & 24 & 100 & 9 & 83 & 5 & 91 & 10 \\
\hline $\begin{array}{l}\text { Learning how to provide mentoring for a } \\
\text { group of people }\end{array}$ & 60 & 16 & 67 & 6 & 67 & 4 & 46 & 5 \\
\hline $\begin{array}{l}\text { Learning how to manage a group of } \\
\text { people }\end{array}$ & 48 & 13 & 44 & 4 & 67 & 4 & 36 & 4 \\
\hline $\begin{array}{l}\text { Learning how to provide support for a } \\
\text { group of people }\end{array}$ & 41 & 11 & 44 & 4 & 50 & 3 & 36 & 4 \\
\hline $\begin{array}{l}\text { Learning how to improve your time } \\
\text { management skills }\end{array}$ & 37 & 10 & 22 & 2 & 84 & 5 & 18 & 2 \\
\hline $\begin{array}{l}\text { Learning how to improve your } \\
\text { presentation skills }\end{array}$ & 33 & 9 & 33 & 3 & 67 & 4 & 9 & 1 \\
\hline
\end{tabular}

*The overall category includes responses from the faculty developer.

5.3 How does the EGSM program impact the teaching practices, mentoring, and career direction of participants?

We divide the following section into the three types of respondents to describe the EGSM program's influence on the participants' teaching practice, mentoring, and career direction. With this approach we hope to identify the key themes for respondents who are working in graduate school, academia, or industry.

\subsubsection{Responses from Former and Current Mentors Who Are Currently in Graduate School}

All EGSMs who are current graduate students answered affirmatively to the question, "Has your experience in the Engineering GSM program influenced your teaching practice?" When asked for examples of how the EGSM program influenced their teaching practice, three major themes were identified. Participants described using active learning techniques in their teaching, being more cognizant of issues that arise in the classroom, and proactively seeking assessment of their own teaching performance.

Additional influences on mentors' teaching practice include reflective teaching, seeking external teaching support and incorporating constructive feedback techniques. One graduate student who 
was a GSI while serving as an EGSM said, "Every semester I have my [EGSM] conduct a midterm student feedback session which always seems to bring out some new ways to improve my teaching."

Another aspect of the program is the support of peers by mentoring on teaching or professional development issues. Participants were asked the following question, "In the past year, have you formally or informally mentored, advised, or consulted coworkers around instructional or professional development issues?" Overwhelmingly, graduate students responded to this question positively $(92 \%, \mathrm{~N}=11)$ due to the fact that $75 \%$ have served as a College of Engineering mentor in the past year. General examples include giving feedback on teaching strategies, providing career counseling/advice and disseminating information about effective ways of teaching and leading.

The graduate students in this study $(\mathrm{N}=12)$ were asked to identify all career choices they are currently considering. All graduate student respondents indicated they were interested in academia (tenured or tenure-track faculty). Approximately $67 \%$ of graduate student respondents $(\mathrm{N}=8)$ were considering a lecturer position, 58.3\% $(\mathrm{N}=7)$ were considering an industry position as an engineer/research scientist, and $50 \%(\mathrm{~N}=6)$ were considering a position in a research laboratory as an engineer/research scientist. In particular, a few graduate students commented on the impact of the EGSM program on their future career plans. One graduate student said, "I was very much set on working in industry until I discovered my strengths as a mentor and a facilitator. I hope to pursue a track in academia." Another graduate student said, "I would like to teach but now I am considering program development more than before. I like the effect of the [EGSM] program and would consider starting something like this at other universities." It is interesting to note that a small percentage (33\%) of EGSMs expressed an interest in faculty/GSI development. This may be attributable to a more realistic view of the profession through their participation in the program.

Figure 2 compares the career options of EGSMs with graduate student instructors $(\mathrm{N}=118)$ who were asked a similar question in Fall 2007. A higher percentage of the EGSMs were interested in academic careers, especially those who are considering lecturer positions. While EGSMs still consider employment in industry or a research laboratory, they are less likely to do so in comparison to the rest of the GSI population. Both groups have comparable percentages of individuals who are interested in a research scientist position in academia, a business career, or a career as a government official. Other career options for one EGSM include post-doctoral positions, while the Fall 2007 Engineering GSIs considered careers in medicine, academic administration or were undecided.

Overall, our survey results show that participants in the EGSM program who are currently in graduate school identify the program as a significant factor in their teaching, mentoring, and career direction. They identify the structure of the training program and the peer consultations experiences as having a large impact on their perceptions. 


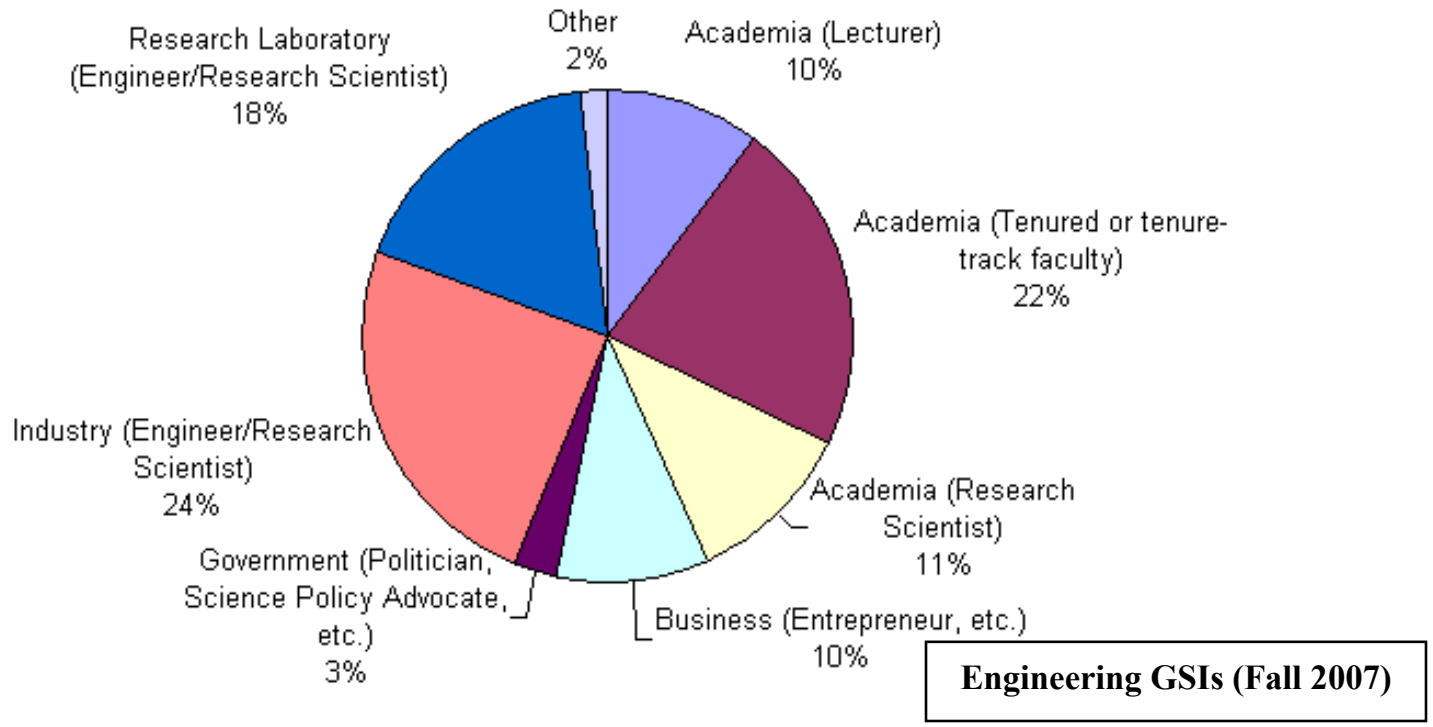

(a)

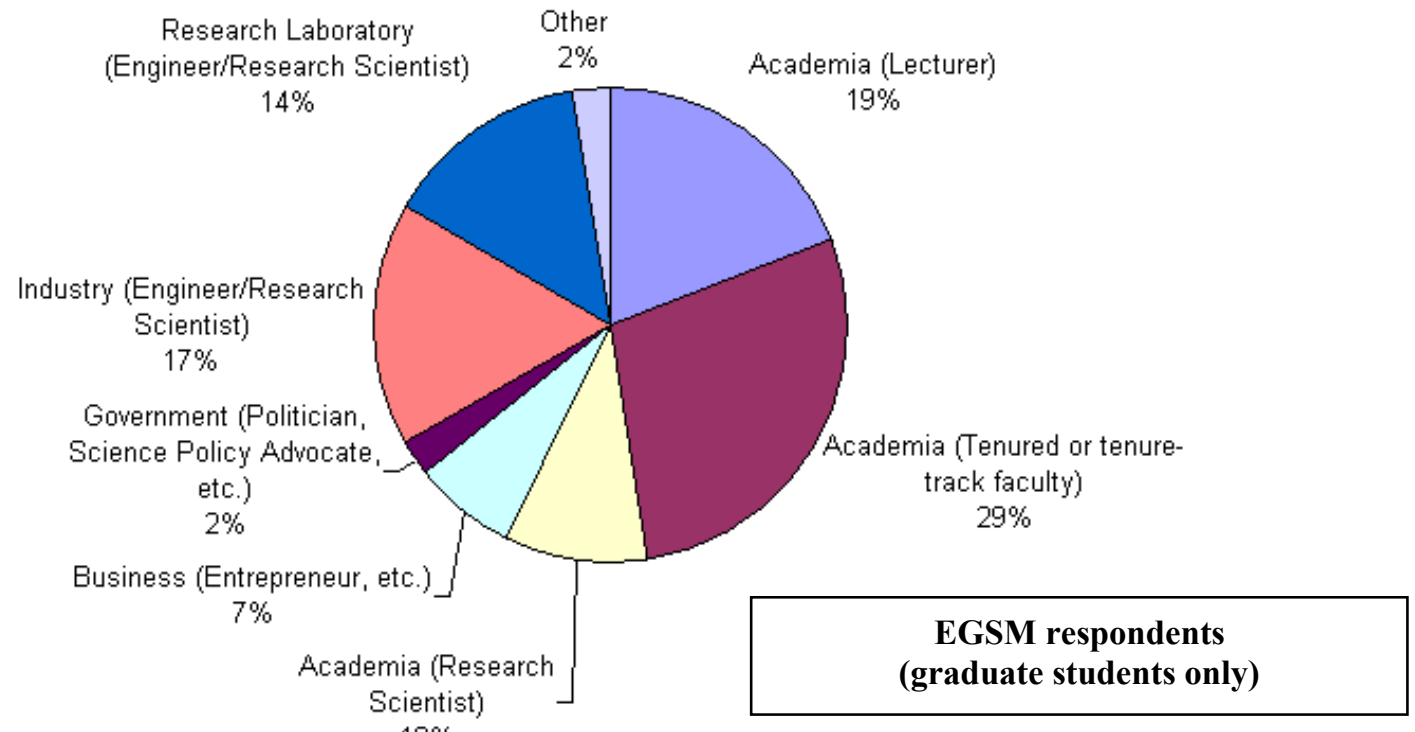

(b)

Figure 2. Comparison of Career Choices considered by (a) Fall 2007 CoE GSIs and (b) Fall 2007 graduate students who have participated in the EGSM program

\subsubsection{Responses of Former Mentors in Academia}

Lecturers or tenured/tenure-track faculty respondents also indicated that the EGSM program influenced their teaching practices. One faculty member said, "My time as [an EGSM] was the only time as a graduate student when I could discuss teaching strategies and ideas for different ways to help students learn (other than the [Engineering pedagogy course]). Because of this, I've become more aware of how the decisions I make in planning and executing my classes influences the students." Similar statements have been made by graduate students who participated in teaching internships. ${ }^{3,5}$ Specific influences on our survey respondents' teaching 
practices include seeking external teaching support, assessing and reflecting on their own teaching, and having an increased awareness of issues that arise in the classroom. One respondent stated, "I immediately got involved with my university's [teaching center]... [by] having their experts assess my teaching and taking courses they offer to continuously improve my teaching skills." Another faculty member conducts classroom observations for the teaching assistants in his courses.

We found that faculty members who have participated in the EGSM program self-report that they are likely to incorporate active learning and classroom assessment techniques. One respondent wrote, "My experience as a mentor is [where] I learned most of the active learning tools and assessment practices I use in my teaching practice." A lecturer stated, "....[This] term, I'm using [in-class] case study activities every 6-8 lecture periods to tie together concepts and themes that give my students a deeper understanding of course material," while another reported, "I ask for feedback more often than I would had I not been a GSM. Also, the way I ask for feedback has been affected: I first ask for things that are going well, then for things that can be improved, and then I leave time in case anyone has any other comments."

All of the faculty respondents formally or informally mentored, advised, or consulted with students, or faculty, around instructional issues. Primarily, faculty disseminated information about effective ways of teaching, discussed pedagogy with peers, and provided career counseling to graduate students. Some gave presentations on topics such as effective uses of instructional technology, team teaching, and teaching quantitative skills. Moreover, 50\% of faculty respondents provided resources on teaching, learning, and higher education to graduate students or other faculty members. Faculty members provided course materials and teaching-related research through journal articles or books on teaching such as McKeachie's Teaching Tips ${ }^{21}$ and Teaching Engineering. ${ }^{22}$ To support graduate student professional development, faculty advised graduate students on course selections and techniques to become better researchers, students, and teachers.

Sixty percent of respondents in academia indicated that the EGSM program influenced their career choice. While this does represent the majority of respondents in academia, the percentage may not be higher due to the fact that many EGSMs already have a strong interest in going into academia prior to enrolling in the program. The primary influence on their career path is associated with the type of institution where they sought employment. The program had a wide range of influence in that it either reinforced the faculty member's interest in working for a primarily teaching institution or it entirely changed their perspective on their career choice. One respondent said, "[The EGSM program allowed] me to see that a career focusing on teaching was what I wanted to do." Another faculty member declared, "To be honest, when I entered the Ph.D. program I had every intention of going back into consulting or industry. However, through my experiences as a GSI and [an EGSM] I discovered that I REALLY like teaching. It literally changed the course of my life."

\subsubsection{Responses of Former Mentors in Industry}

Considering that many engineering GSIs are interested in pursing nonacademic careers, it is important to get a sense of how the program has impacted alumni in industry. In the Fall 2007 
survey of CoE GSIs, ${ }^{10} 99$ GSIs (out of 121 respondents) indicated a non-academic career choice (Figure 2a). Due to the small number of industry respondents for our EGSM survey, we have only identified general trends. However, the data still suggest compelling indicators that we feel would still be consistent with a larger data set. Alumni currently in industry point to the EGSM program as having a considerable impact on their mentoring and managerial skills in industry due to the structure of the training program and the peer consultations experiences. While the impact on traditional classroom teaching experiences is not as strong, respondents are more likely to apply their teaching practices outside the classroom.

Over $80 \%$ of the EGSM alumni respondents working in industry indicated that they informally or formally mentored coworkers by providing feedback on research presentations and discussing research ideas with new hires and interns. One respondent has "assisted coworkers in the presentation of research/academic material," while another has "supported people moving into new research areas and new hires to his group." Recall that EGSMs present teaching-related seminars as mentors. These experiences coupled with their knowledge of student learning enhance their ability to present technical research and mentor others as well.

Personal professional development skills are highlighted most often by respondents in industry. As we mentioned above, all industry respondents affirmed that the EGSM program improved their time management skills. In particular, they mention how they appreciated being able to work with people with different perspectives and learn how to be flexible in the work environment. One respondent said, "It helped me realize the value I place for personal interaction, and gave me a better perspective on people and their viewpoints." Being able to work in a diverse workplace is an essential skill for engineers in industry as many companies operate in the global market. $^{23}$

All industry members wrote that the EGSM program influenced their teaching practices. In fact, some express their desire to expand on their work responsibilities to incorporate the traditional classroom experiences. One industry member indicated that he had an adjunct teaching position where he is able to bring the teaching experiences from the EGSM program to the classroom. Another respondent from industry indicated that he shared course notes and tips on teaching informally. Unlike their academic counterparts, the majority of industry respondents have not provided teaching-related resources. This result is not surprising due to the nature of their work responsibilities. However, one respondent said, "I don't teach or even present much, but I try to be observant of different learning styles."

Over $80 \%$ of the EGSM alumni respondents working in industry indicated that the program influenced their career path. Like faculty respondents, the impact of the program varied. Some indicated that they still have desires to go into academia. Another respondent described how the program "brought new dimension to my career, opened up considerable professional opportunities - both internal and external - with regards to content preparation and delivery, and being [able] to provide professional training-related service offerings." 


\section{Conclusions}

The Engineering GSI Mentor (EGSM) program at the University of Michigan benefits not only the mentees, but the mentors as well. We have summarized the services that mentors provide and the training that they receive to provide the framework for this study. In particular, we have surveyed current and former members to determine that this program impacts the mentors' teaching practices, mentoring style, and career pathway. As one participant said, "As [an EGSM] I have had the opportunity to mentor many graduate students in their positions as GSIs. I personally believe this has been a two-way road in terms of the development of both parties. I am able to gain insights into issues that arise as being a GSI and I am able to facilitate resolutions."

The EGSMs become more reflective about their teaching inside and outside of the classroom. Where professors are more likely to focus on ways to improve their classroom communication, research scientists and engineers apply their knowledge about effective means to deliver information during their research presentations. In this manner, graduate students who would not necessarily have the opportunity to think about pedagogy during their matriculation through graduate school are now equipped to apply this knowledge regardless of their career path. Additionally, program participants continue to provide mentoring beyond their tenure in the program and value constructive feedback - both giving and receiving. We believe the opportunity to work with peers is a unique experience that mentors value and will ultimately support their roles as future professionals.

\section{Acknowledgements}

We would like to thank Jack Hu from the office of the Associate Dean for Graduate Research and Education for his commitment to the University of Michigan's Engineering GSI mentor program. Additionally, we are grateful for the following program managers from the University of Michigan's Center for Research on Learning and Teaching (CRLT) who have provided guidance and support for this work: Dr. Cindy Finelli, Dr. Deborah Meizlish, Dr. Chris O’Neal, Dr. Mary Piontek, and Dr. Mary Wright.

\section{References}

1. O'Neal, C. \& Karlin, J. (2004). Graduate student mentors: meeting the challenges of the ongoing development of graduate student instructors. In C. Wehlburg \& S. Chadwick-Blossey (Eds), To Improve the Academy: Vol. 22. Resources for faculty, instructional and organizational development, (pp. 320-332). Bolton, MA: Anker.

2. Hancock, T. \& Norton, J. (2004, June). Experiences of Graduate Student Mentors Mentoring Graduate Student Instructors. Proceedings of the 2004 American Society for Engineering Education Annual Conference \& Exposition. Salt Lake City, Utah.

3. Phillips, J. \& Murphy, T. (2005, June). Mentoring Graduate Students in Engineering Education through Team Teaching. Proceedings of the 2005 ASEE Annual Conference and Exposition. Portland, Oregon.

4. Norris, P. \& Palmer, S. (1998), Effectiveness of Woodruff School Doctoral Teaching Intern Program. Journal of Engineering Education, 87 (3), 223-226.

5. Murphy, T. \& Phillips, J. (2005, June). Preparing for an Academic Career through Team Teaching as a Graduate Student. Proceedings of the 2005 ASEE Annual Conference and Exposition. Portland, Oregon.

6. Sherwood, J., Petersen, J., \& Grandzielwski, J. (1997). Faculty Mentoring: A Unique Approach to Training Graduate Students How to Teach. Journal of Engineering Education, 86 (2), 119-123.

7. University of Texas at Austin Center for Teaching Effectiveness.(2008).Retrieved January 13, 2008, from http://www.utexas.edu/academic/cte/

8. Bollis-Pecci, T.S. \& Walker, K.L. (1999). Peer Mentoring Perspectives in GTA Training: A Conceptual Roadmap. Journal Graduate Teaching Assistant Development, 7(1), 27-17. 
9. The University of Colorado at Boulder Graduate Teacher Program. Retrieved January 13, 2008, from $\mathrm{http}: / / \mathrm{www} . c o l o r a d o . e d u / g t p / l e a d /$

10. Harvard University, Derek Bok Center for Teaching and Learning (2008). Retrieved January 13, 2008, from http://bokcenter.harvard.edu/

11. Pinder-Grover, T. \& Ledbetter, A. (2008). CRLT North Report for the College of Engineering:Engineering GSI Survey - Fall Term 2007. Ann Arbor, MI: Author.

12. Center for Research on Learning and Teaching North (2007). CRLT North Report for the College of Engineering 2006-2007. Ann Arbor, MI: Author.

13. Pinder, T. (2007). Teaching Practice: Emphasis on Active Learning. In Ross, C. and Dunphy, J (Eds ), Strategies for Teaching Assistant and International Teaching Assistant Development: beyond micro teaching, (pp. 76-79), San Francisco, CA: Jossey-Bass.

14. Nyquist, J. \& Sprague, J. (1998). Thinking Developmentally about TA s, In Marincovich, M., Prostko, J. and Stout, F. (Eds), The Professional Development of Teaching Assistants, (pp. 61-88), Boston, MA: Anker.

15. Border, L. (1997). Creative art of effective consultation, In. K. Brinko and R. Menges (Eds), Practically Speaking, (pp. 17-24). Stillwater Oklahoma: New Forus Press.

16. Bauer,G. (1997). Effects of Classroom Environments, In. K. Brinko and R. Menges (Eds), Practically Speaking, (pp. 197-210). Stillwater Oklahoma: New Forus Press.

17. Felder, R.M. and Silverman L.K. (1988). Learning styles and teaching styles in engineering education, Engineering Education, 78(7), 674-681.

18. Finelli, C. J., Gottfried, A.C., Kaplan, M.L., Mesa, V.M., O'Neal, C.M., \& Piontek, M.E. (2006, June). Evaluating methods to improve teaching in engineering. Proceedings of the 2006 ASEE Annual Conference and Exposition. Chicago, IL.

19. Carpenter, D.D., Harding, T.S., Finelli, C.J., Montgomery, S.M., \& Passow, H.J. (2006). Engineering students' perceptions of and attitudes towards cheating. Journal of Engineering Education, 95(3), 181-194.

20. Meizlish, D., \& Wright, M. (2007, October). "Graduate teaching consultants: 'Quick starters' in faculty development." Annual meeting of the Organization of Professional Organizers and Developers, Pittsburgh, PA.

21. McKeachie, W. J. (2006). Teaching tips (12th ed.). Boston: Houghton Mifflin.

22. Wankat, P. \& Oreovicz, F. (1993). Teaching Engineering, New York: McGraw Hill.

23. Loftus, M. (2007). Cream of the Crop. ASEE Prism (28-33).

Appendix

The following survey questions were included in this study:

1. Do you wish to go on to complete the survey?

- I consent to move on to this survey. I understand that I may skip any question I do not wish to answer.

- I do not consent

2. Please describe your current career: (choose the one that best applies, but feel free to write additional clarifications in the Other box)

- Graduate student

- Lecturer

- Tenured or tenure-track faculty

- Faculty or graduate student development professional (working in a teaching center)

- Higher education administrator (other than faculty/graduate student development)

- Research Scientist in Academia

- Research Scientist/Engineer at a National Laboratory

- Research Scientist/Engineer in Industry

- Other 
3. What career paths are you currently considering for your future? (Choose all that apply. Question for graduate student respondents only)

- Academia (Lecturer)

- Academia (Tenured or tenure-track faculty)

- Academia (Faculty or GSI development)

- Academia (Higher Education Administration)

- Academia (Research Scientist)

- Business (Entrepreneur, etc.)

- Government (Politician, Science Policy Advocate, etc.)

- Industry (Engineer/Research Scientist)

- Research Laboratory (Engineer/Research Scientist)

- Other (please specify

4. In what type of institution do you work (for those who indicated they are in higher education)?

- Research university

- Comprehensive/master's university

- Liberal arts college

- Community/two-year college

- Other (please specify)

5. Please choose the response that best applies to your teaching at the postsecondary level (for those who indicated they are in higher education).1

- I currently teach at the post secondary level

- In the past year, I taught at the postsecondary level

- It's been 1-2 years since I taught at the postsecondary level

- It's been over 2 years since I taught at the post secondary level

6. Has your experience in the Engineering GSM program influenced your teaching practice? Yes/No

7. Please give examples of the way your experience in the Engineering GSM program has influenced your teaching practice (Note: for people who said yes to the previous question)

8. In the past year, have you formally or informally mentored, advised, or consulted with other graduate students or faculty around instructional or professional development issues? Yes/No

9. Please give some examples of how you have mentored other graduate students or faculty around instructional or professional development issues. (e.g., the type of assistance you were able to provide). (Note: for people who said yes to the previous question)

10. In the past year, have you provided resources on teaching, learning, or higher education to other graduate students or faculty? Yes/No

11. Please give some examples of the types of resources you have provided on topics pertaining to teaching, learning, or higher education to other graduate students or faculty. (Note: for people who said yes to the previous question)

12. Did your involvement in the Engineering GSM program influence your career path (i.e., your intended or current choice of career type or setting)? Yes/No

13. In what ways did your involvement in the Engineering GSM program influence the direction of your career? (Note: for people who said yes to the previous question) 
14. What aspects of the training that you received as a GSM were most valuable to you when you were a GSM? (Check all that apply)

- Midterm student feedback (MSF) and classroom observation training

- Practice teaching facilitation training

- GSM biweekly meetings

- GSM roundtable discussions

- Mentoring of new GSMs from experienced GSMs

- Other (Please specify)

15. Which of the following experiences were either developed or enhanced as a result of your participation in the EGSM program? (Check all that apply)

- Learning more about teaching and student learning (pedagogy)

- Learning how to handle different classroom challenges

- Learning how to improve your own teaching in the classroom

- Learning how to provide feedback to others

- Learning how to manage a group of people

- Learning how to provide support for a group of people

- Learning how to provide mentoring for a group of people/individuals

- Learning how to improve your time management skills

- Learning how to improve your presentation skills

- Other (Please specify)

16. Please describe any other influence of the Engineering GSM program on you personally that you feel is significant.

17. May we contact you to follow up on your answers?

- Yes/No

18. If yes, please enter your name, phone and email address in the space provided below. 